\title{
Tolerance to endoplasmic reticulum stress mediates cisplatin resistance in human ovarian cancer cells by maintaining endoplasmic reticulum and mitochondrial homeostasis
}

\author{
YE XU ${ }^{1,2^{*}}$, CHUNYAN WANG $^{1 *}$, JING SU $^{3}$, Q XIE $^{3}$, LIWEI MA ${ }^{3}$, LINCHUAN ZENG $^{1}$, \\ YANG YU ${ }^{1}$, SHIBING LIU ${ }^{1}$, SONGYAN LI ${ }^{1}$, ZHIXIN LI $^{2}$ and LIANKUN SUN ${ }^{3}$ \\ ${ }^{1}$ Medical Research Laboratory, and ${ }^{2}$ Department of Histology and Embryology, Jilin Medical University, Jilin City, \\ Jilin 132013; ${ }^{3}$ Department of Pathophysiology, College of Basic Medical Sciences, Jilin University, \\ Changchun, Jilin 130021, P.R. China
}

Received June 11, 2015; Accepted August 28, 2015

DOI: $10.3892 /$ or.2015.4283

\begin{abstract}
The mechanism of cisplatin resistance in ovarian cancer is not fully understood. In the present study, we showed a critical role for endoplasmic reticulum (ER) stress tolerance in mediating cisplatin resistance in human ovarian cancer cells. We found cisplatin to inhibit the proliferation of two ovarian cancer cell lines: cisplatin-sensitive SKOV3 cells and cisplatin-resistant SKOV3/DDP cells. However, the effect was greater in the cisplatin-sensitive SKOV3 cells. Cisplatin treatment induced ER stress in the SKOV3 cells but not in the SKOV3/DDP cells. Cisplatin-induced $\mathrm{Ca}^{2+}$ flow from the ER into mitochondria caused mitochondrial calcium overload, which amplified proapoptotic signaling in the cisplatin-sensitive SKOV3 cells. ER stress-mediated apoptosis and mitochondrial pathway-dependent apoptosis were induced in the cisplatin-sensitive SKOV3 cells, but not in the cisplatin-resistant SKOV3/DDP cells. Moreover, there were more ER-mitochondria contacts in the cisplatin-treated SKOV3 cells. Collectively, our data indicated that tolerance to cisplatin-induced ER stress inhibits ER stress-mediated apoptosis, prevents an imbalance in ER and mitochondrial calcium homeostasis and maintains cell survival, thus leading to cisplatin resistance in ovarian cancer cells.
\end{abstract}

Correspondence to: Professor Zhixin Li, Department of Histology and Embryology, Jilin Medical University, 5 Jilin Street, Jilin City, Jilin 132013, P.R. China

E-mail: lzx-62@163.com

Professor Liankun Sun, Department of Pathophysiology, College of Basic Medical Sciences, Jilin University, 126 Xinmin Street, Changchun, Jilin 130021, P.R. China

E-mail:sunlk@jlu.edu.cn

*Contributed equally

Key words: ER stress, apoptosis, cisplatin resistance, ovarian cancer

\section{Introduction}

Ovarian cancer is a common cancer of the female reproductive organs, and is associated with the highest death rate among all gynecological cancers (1). Cisplatin chemotherapy and adjuvant therapy are common in ovarian cancer, and drug resistance is a major cause of death (1-3). Cisplatin resistance is mostly a secondary effect, and its mechanism is unclear. Cisplatin resistance may be associated with the altered regulation of multiple signaling pathways, including downregulation of apoptotic signals and activation of pro-survival signals (3-5). Recent studies have shown that cisplatin can induce endoplasmic reticulum (ER) stress-associated apoptosis, and that ER stress tolerance may be involved in cisplatin resistance (6-9).

A variety of physiological and pathological conditions, including viral infection, hypoxia, oxidative damage and antitumor therapy, can induce ER stress $(10,11)$. ER stress can activate ER stress-related proapoptotic molecules such as growth arrest and DNA damage-inducible transcript 3 (DDIT3) (also known as CHOP) and caspase-12, and induce the expression and activation of pro-survival molecules such as GADD34 and $78 \mathrm{kDa}$ glucose-regulated protein (Grp-78). The balance between these processes determines cellular fate, i.e., adaptation or apoptosis (11-13). ER-mediated apoptosis involves at least two mechanisms: the unfolded protein response (UPR) and calcium signaling (12).

Calcium ions can function as mitogenic or proapoptotic messengers, depending on their intracellular location and cytoplasmic concentration $(14,15)$. The storage, release and uptake of all non-muscle cell calcium ions are subject to ER regulation. Disrupted ER calcium homeostasis can induce cellular apoptosis. There is a crosstalk between the UPR and ER calcium signaling (16). Excessive ER stress may synergize with mitochondrial cytochrome $c$ release, leading to caspase activation and apoptosis (17). Close contact between the ER and mitochondria membranes enables the exchange of lipid, calcium ions and glycosylated proteins (18-20). ER inositol trisphosphate receptor (IP3R) channel opening has a destabilizing role on mitochondrial calcium balance, and ER $\mathrm{Ca}^{2+}$ channel activity regulates cellular susceptibility 
to ER stress $(21,22)$. However, it is unclear whether the ER stress-mediated apoptosis induced by cisplatin regulation of the UPR and calcium signaling are involved in ovarian cancer drug resistance.

In the present study, we found that cisplatin resistance in ovarian carcinoma is linked to ER stress tolerance. The intensity of ER stress induced by cisplatin was weaker in cisplatin-resistant SKOV3/DDP ovarian cancer cells than in the parental cisplatin-sensitive SKOV3 cells. Both ER stress-mediated apoptosis and mitochondrial pathway-mediated apoptosis were induced in the cisplatin-sensitive SKOV3 cells, but not in the cisplatin-resistant SKOV3/DDP cells. Cisplatin-induced $\mathrm{Ca}^{2+}$ flow from the ER to mitochondria led to mitochondrial calcium overload, which amplified proapoptotic signaling in the cisplatin-sensitive SKOV3 cells. Tolerance to cisplatininduced ER stress involved the preservation of ER and mitochondria calcium homeostasis, which maintained cell survival and led to cisplatin resistance in ovarian cancer cells.

\section{Materials and methods}

Cell culture. The cisplatin-sensitive human ovarian cancer cell line SKOV3 and the cisplatin-resistant clone SKOV3/ DDP were obtained from the Chinese Academy of Medical Sciences and the Peking Union Medical College, respectively. Cells were cultured at $37^{\circ} \mathrm{C}$ with $5 \% \mathrm{CO}_{2}$ in RPMI-1640 medium (Gibco, Carlsbad, CA, USA) supplemented with $10 \%$ fetal bovine serum (FBS; Invitrogen, Carlsbad, CA, USA). SKOV3/DDP cells were maintained in the same medium containing $1 \mu \mathrm{g} / \mathrm{ml}$ cisplatin (Sigma, St. Louis, MO, USA) to maintain the multidrug-resistant phenotype.

Cell viability assays. Cell viability was determined by the 3-(4,5-dimethylthiazol-2-yl)-2,5-diphenyltetrazolium bromide (MTT) assay. Exponentially growing cells were seeded into 96-well culture plates in $100 \mu \mathrm{l}$ medium at a density of $1 \times 10^{4}$ cells/well. After 16-24 h, varying concentrations of cisplatin were added to quadruplicate wells and cells were incubated for 24 or $48 \mathrm{~h}$. For the MTT assays (Beyotime, Shanghai, China), $20 \mu \mathrm{l} /$ well MTT [5 $\mathrm{mg} / \mathrm{ml}$ in phosphate-buffered saline (PBS)] was added to the cells and incubated for $4 \mathrm{~h}$. Dimethylsulfoxide (150 $\mu \mathrm{l} /$ well; Beijing Chemical Industry, Beijing, China) was then added, the plates were shaken at room temperature for $10 \mathrm{~min}$, and the absorbance was measured at a 570-nm wavelength using a microplate reader ( BioTek Instruments, Winooski, VT, USA).

Immunofluorescence staining and confocal laser microscopy. Cells were seeded onto coverslips into 24 -well plates at a density of $5 \times 10^{4}$ cells/well and allowed to recover overnight. After treatment with $6 \mu \mathrm{g} / \mathrm{ml}$ cisplatin for 0 or $24 \mathrm{~h}$, the cells were fixed with $4 \%$ paraformaldehyde, stained with the Hoechst 33342 (2 $\mu \mathrm{g} / \mathrm{ml}$; Sigma) nuclear stain for $30 \mathrm{~min}$, and washed in PBS; chromatin condensation was examined by an Olympus FV1000 confocal laser microscope (Olympus, Tokyo, Japan). Expression of Grp78, protein disulfide isomerase (PDI) and active caspase-3, and PDI colocalization with voltage-dependent anion-selective channel protein 1 (VDAC1), IP3R and mitochondria were examined by indirect immunofluorescence. For this, the cells were cultured on coverslips overnight, treated with $6 \mu \mathrm{g} / \mathrm{ml}$ cisplatin for different time periods, and then rinsed three times with PBS. The cells were then fixed with $4 \%$ paraformaldehyde for $20 \mathrm{~min}$, permeabilized with $0.1 \%$ Triton $\mathrm{X}-100$ for $5 \mathrm{~min}$, blocked with $5 \%$ bovine serum albumin, and incubated with a primary antibody (anti-Grp78, anti-PDI, anti-active caspase-3, anti-VDAC1, anti-IP3R; all used at 1:100 dilution; anti-Grp78, anti-PDI and anti-active caspase-3 were obtained from Santa Cruz Biotechnology, Santa Cruz, CA, USA; anti-VDAC1 and anti-IP3R were obtained from Abcam, Hong Kong; and MitoTracker Red was obtained from Invitrogen) overnight at $4^{\circ} \mathrm{C}$. The next day, coverslips were incubated with the Alexa Fluor 488/546-conjugated secondary antibody (1:400 dilution; Molecular Probes, Eugene, OR, USA) for $1 \mathrm{~h}$, and stained with Hoechst $33342(2 \mu \mathrm{g} / \mathrm{ml})$ for $2 \mathrm{~min}$, followed by three washes in PBS. After mounting onto slides, the cells were examined using an Olympus FV1000 confocal laser microscope.

Flow cytometric analysis. The Muse ${ }^{\mathrm{TM}}$ Annexin V Dead Cell kit (EMD Millipore Corporation, Hayward, CA, USA) was used to monitor cell death. Exponentially-growing SKOV3 and SKOV3/DDP cells were seeded into 6-well culture plates at a density of $2 \times 10^{5}$ cells/well. Following exposure to experimental conditions, the cells were trypsinized and resuspended in RPMI-1640 medium with $10 \%$ FBS at a concentration of $1 \times 10^{6}$ cells $/ \mathrm{ml}$. Cells were incubated with Annexin V and Dead Cell reagent in a darkroom at room temperature for $20 \mathrm{~min}$. Finally, the samples were measured using the Muse ${ }^{\mathrm{TM}}$ Cell Analyzer (EMD Millipore Corporation). All experiments were performed in triplicate.

Western blot analysis. Whole cell protein extracts were prepared using cell lysis buffer $(50 \mathrm{mM}$ Tris- $\mathrm{HCl}, \mathrm{pH} 7.5$, $150 \mathrm{mM} \mathrm{NaCl}, 1 \mathrm{mM} \mathrm{Na}{ }_{2}$ EDTA, $1 \mathrm{mM}$ EDTA, $1 \%$ Triton, $2.5 \mathrm{mM}$ sodium pyrophosphate, $1 \mathrm{mM} \beta$-glycerophosphate, $1 \mathrm{mMNa}_{3} \mathrm{VO}_{4}, 1 \mathrm{mM} \mathrm{NaF}, 1 \mu \mathrm{g} / \mathrm{ml}$ leupeptin and $1 \mathrm{mM}$ PMSF) for western blotting. The protein concentration was quantified using a Bradford protein assay kit (Bio-Rad, Hercules, CA, USA). For cytoplasmic protein extraction, the cells were harvested, washed with ice-cold PBS and sedimented for $5 \mathrm{~min}$ at $600 \mathrm{x} \mathrm{g}$ at $4^{\circ} \mathrm{C}$. Cells were then incubated in cell lysis buffer (150 mM NaCl, $1 \mathrm{mM}$ EDTA, $10 \mathrm{mM}$ HEPES, $1 \mathrm{mM}$ PMSF and $0.6 \% \mathrm{NP}-40)$. Cell lysates were sonicated, incubated for $15 \mathrm{~min}$ on ice, and then clarified at $700 \mathrm{x} \mathrm{g}$ for $10 \mathrm{~min}$ at $4^{\circ} \mathrm{C}$. The supernatant was centrifuged at $14,000 \mathrm{x} \mathrm{g}$ for another $30 \mathrm{~min}$ at $4^{\circ} \mathrm{C}$; cytoplasmic proteins were present in the supernatant. For western blot analysis, lysate proteins $(30-50 \mu \mathrm{g})$ were resolved by 8,10 or $15 \%$ SDS-polyacrylamide gel electrophoresis and transferred onto Immobilon-P membranes (EMD Millipore, Billerica, MA, USA). Membranes were then blocked with $5 \%$ non-fat dry milk in buffer $(10 \mathrm{mM}$ Tris- $\mathrm{HCl}$, $\mathrm{pH} 7.6,100 \mathrm{mM} \mathrm{NaCl}$ and $0.1 \%$ Tween-20) for $1 \mathrm{~h}$ at room temperature and incubated with the relevant primary antibody overnight at $4^{\circ} \mathrm{C}$. Anti-Grp78 and anti-PDI antibodies (used at 1:200 dilution) were obtained from Santa Cruz Biotechnology. Anti-ATF4, DDIT3/CHOP, anti-cytochrome $c$, anti-caspase-3 and anti-caspase-4 (used at 1:1,000 dilution) and CTR1 were obtained from Abcam (Cambridge, UK). Anti- $\beta$-actin antibody (1:1,000 dilution) was obtained from ProteinTech 

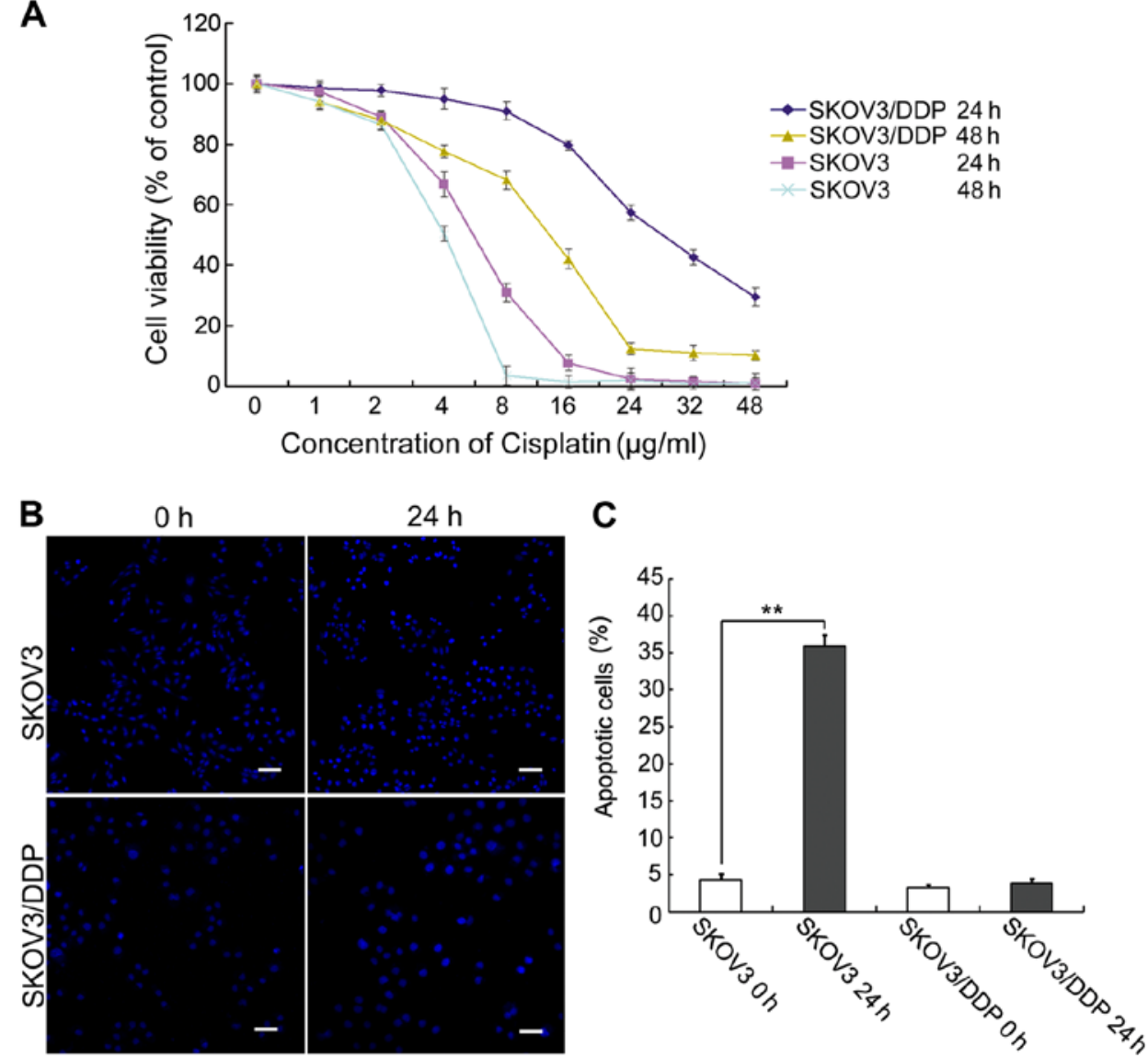

Figure 1. Cisplatin inhibits human ovarian cancer cell proliferation. (A) SKOV3 and SKOV3/DDP cells were treated with varying doses of cisplatin for 24 or $48 \mathrm{~h}$. Cell viability was determined by the MTT assay. Data are presented as means $\pm \mathrm{SD}, \mathrm{n}=3$. (B) Cells were treated with $6 \mu \mathrm{g} / \mathrm{ml}$ cisplatin for 0 or $24 \mathrm{~h}$ and then stained with Hoechst 33342. Cell nuclear morphology was observed by confocal microscopy (scale bar, $50 \mu \mathrm{m}$ ). (C) Quantitation of apoptotic cells. Data are presented as means $\pm \mathrm{SD}, \mathrm{n}=3, \stackrel{* *}{\mathrm{P}}<0.01$ vs. control.

Group (Chicago, IL, USA). Membranes were then incubated with horseradish peroxidase-conjugated secondary antibody (Thermo Fisher Scientific, Waltham, MA, USA) at 1:2,000 dilution for $1 \mathrm{~h}$ at room temperature. Immunodetection was performed using enhanced chemiluminescence reagents (Thermo Scientific, Rockford, IL, USA) and images were captured using a Syngene Bio Imaging System (Synoptics, Cambridge, UK). Specific proteins were quantified by densitometry using Quantity One software (Bio-Rad Laboratories), normalized to actin, and presented as the mean \pm SD of three independent experiments.

Calcium concentration analysis. The $\mathrm{Ca}^{2+}$-sensitive fluorescent dyes Fluo-4/AM (Molecular Probes) and Rhod-2/AM (AAT Bioquest, Sunnyvale, CA, USA) were used to measure the $\mathrm{Ca}^{2+}$ concentration according to the manufacturer's instructions. Before exposure to different experimental conditions, the cells were incubated with Fluo-4/AM or Rhod-2/AM for $30 \mathrm{~min}$ at $37^{\circ} \mathrm{C}$. Cell samples were then analyzed by confocal laser microscopy. All experiments were performed in triplicate.

$J C-1$ staining. The mitochondrial membrane potential was examined by JC-1 staining kit (Beyotime Institute of Biotechnology, China). After cisplatin treatment, the cells were incubated with a $\mathrm{JC}-1$ working solution at $37^{\circ} \mathrm{C}$ in the dark for $20 \mathrm{~min}$ and then observed by confocal microscopy.
In healthy cells, where mitochondrial membranes remain depolarized, JC-1 forms complexes of J aggregates, which are seen as punctate red fluorescence at the 590-nm emission wavelength; however, in apoptotic cells, JC-1 remains in the monomeric form, and is seen as diffused green fluorescence at the 530-nm emission wavelength.

Statistical analysis. Experiments were performed at least three times, and data are presented as means \pm SD. Data analysis was performed using one-way ANOVA. Tukey's post-hoc test was used to determine the statistical significance in all pairwise comparisons of interest. $\mathrm{P}<0.05$ was considered to represent a statistically significant difference.

\section{Results}

Cisplatin inhibits proliferation and induces apoptosis in the ovarian cancer cells. We compared cisplatin sensitivity in cisplatin-sensitive SKOV3 cells and cisplatin-resistant SKOV3/DDP cells. Both cell types were treated with increasing doses of cisplatin for 24 or $48 \mathrm{~h}$, and then growth inhibition was examined using MTT assays. We found that cisplatin inhibited the proliferation and/or survival of both ovarian cancer cell lines (Fig. 1A). This result confirmed that cisplatin-sensitive SKOV3 cells were more sensitive to cisplatin than cisplatin-resistant SKOV3/DDP cells. 


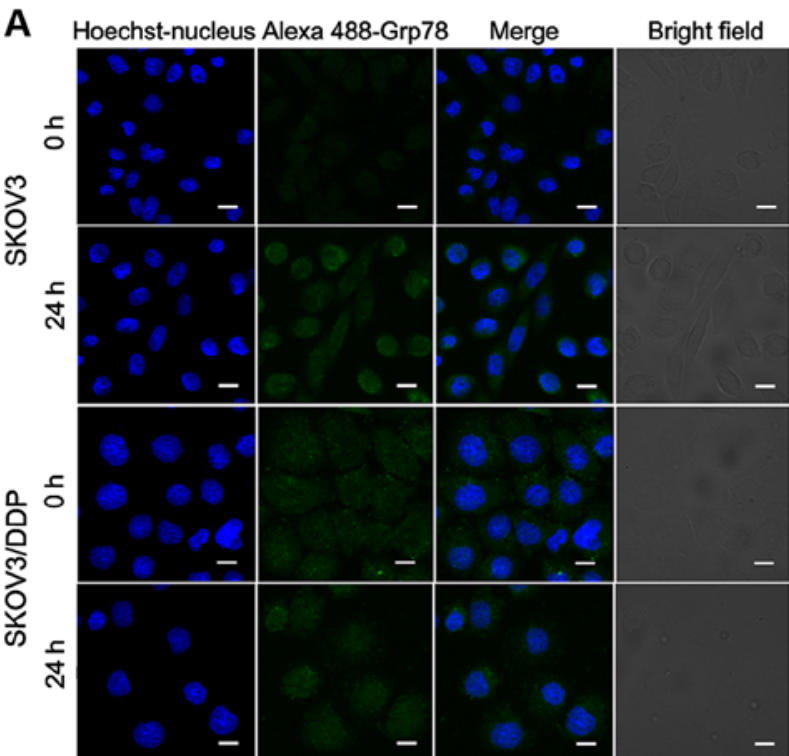

B

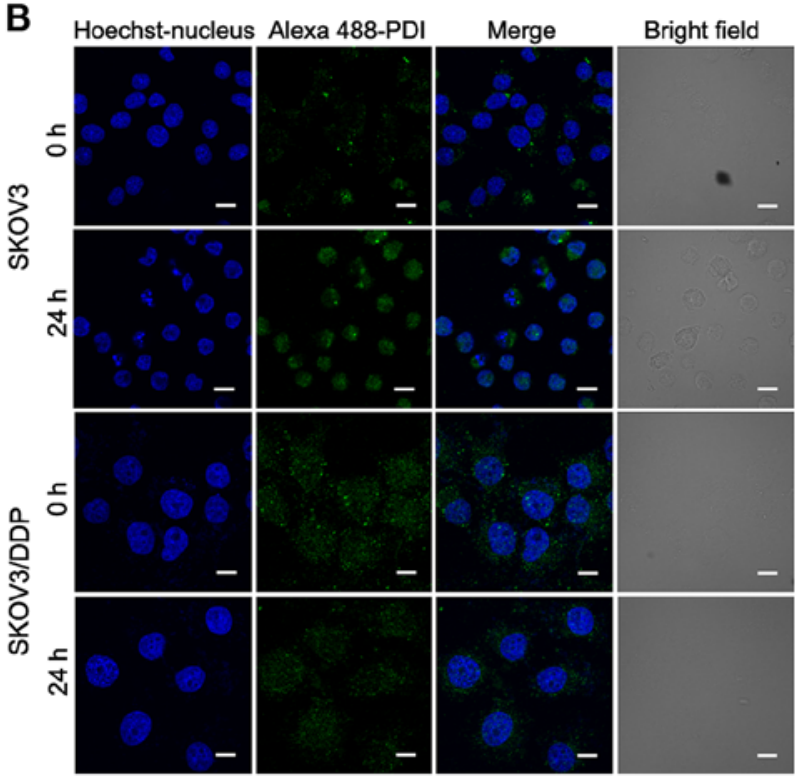

C Cisplatin $\frac{\text { SKOV } 3}{0 \mathrm{~h} 6 \mathrm{~h} 12 \mathrm{~h} 24 \mathrm{~h}} \frac{\text { SKOV3/DDP }}{0 \mathrm{~h} 6 \mathrm{~h} 12 \mathrm{~h} 24 \mathrm{~h}}$

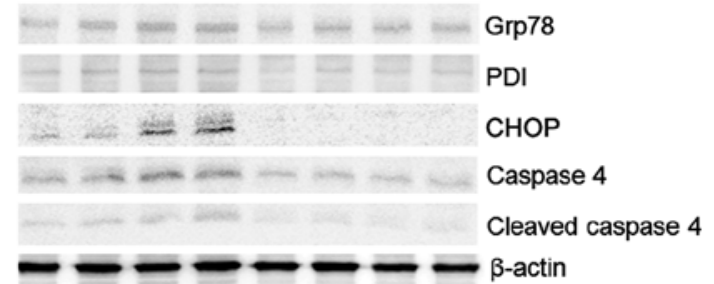

D

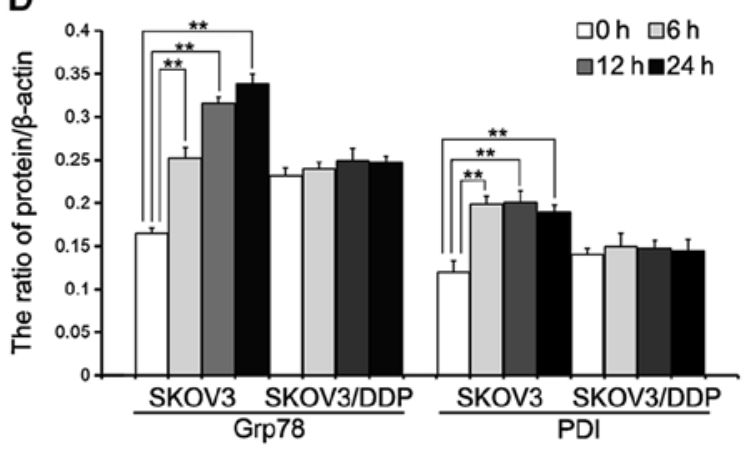

E

$\mathbf{F}$

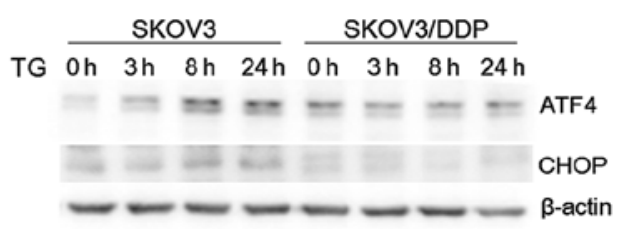

$\square 0 \mathrm{~h} \square 6 \mathrm{~h}$

$\square 12 \mathrm{~h}=24 \mathrm{~h}$

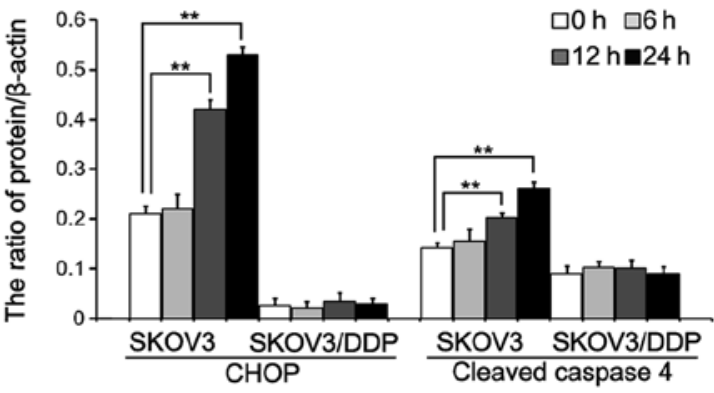

G

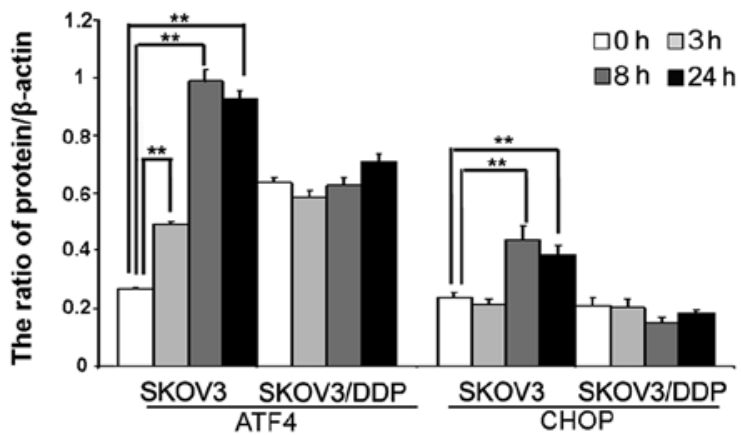

Figure 2. Cisplatin triggers ER stress-associated cell death in SKOV3 cells. (A) Cells were treated with $6 \mu \mathrm{g} / \mathrm{ml}$ cisplatin for 0 or $24 \mathrm{~h}$. The cytoplasmic distribution of Grp78 was observed by confocal microscopy (scale bar, $10 \mu \mathrm{m}$; Alexa Fluor 488-conjugated secondary antibody). (B) Cells were treated with $6 \mu \mathrm{g} / \mathrm{ml}$ cisplatin for 0 or $24 \mathrm{~h}$. The cytoplasmic distribution of PDI was observed by confocal microscopy (scale bar, $10 \mu \mathrm{m}$; Alexa Fluor 488 -conjugated secondary antibody). (C) Western blot analysis of Grp78, PDI, DDIT3/CHOP, caspase-4 and cleaved caspase-4 protein expression in both cell lines after cisplatin treatment. (D) Quantitation of Grp78 and PDI proteins. Data are presented as means $\pm \mathrm{SD}, \mathrm{n}=3$. ${ }^{* *} \mathrm{P}<0.01$ vs. control. (E) Quantification of DDIT3/CHOP and cleaved caspase- 4 protein. Data are presented as means $\pm \mathrm{SD}, \mathrm{n}=3 .{ }^{* * *} \mathrm{P}<0.01$ vs. control. (F) Western blot analysis of ATF4 and DDIT3/CHOP protein expression in both cell lines after thapsigargin (TG) treatment. (G) Quantitation of ATF4 and DDIT3/CHOP proteins. Data are presented as means \pm SD, $n=3$. ${ }^{* * *} \mathrm{P}<0.01$ vs. the control.

Based on the results of the MTT assay and previous studies (9), both cell lines were treated with $6 \mu \mathrm{g} / \mathrm{ml}$ cisplatin for 0 or $24 \mathrm{~h}$, and apoptotic chromatin condensation was examined by Hoechst 33342 staining (Fig. 1B). Cisplatin-induced apoptotic chromatin condensation was clearly observed in the SKOV3 cells, but not in the SKOV3/DDP cells. We also 

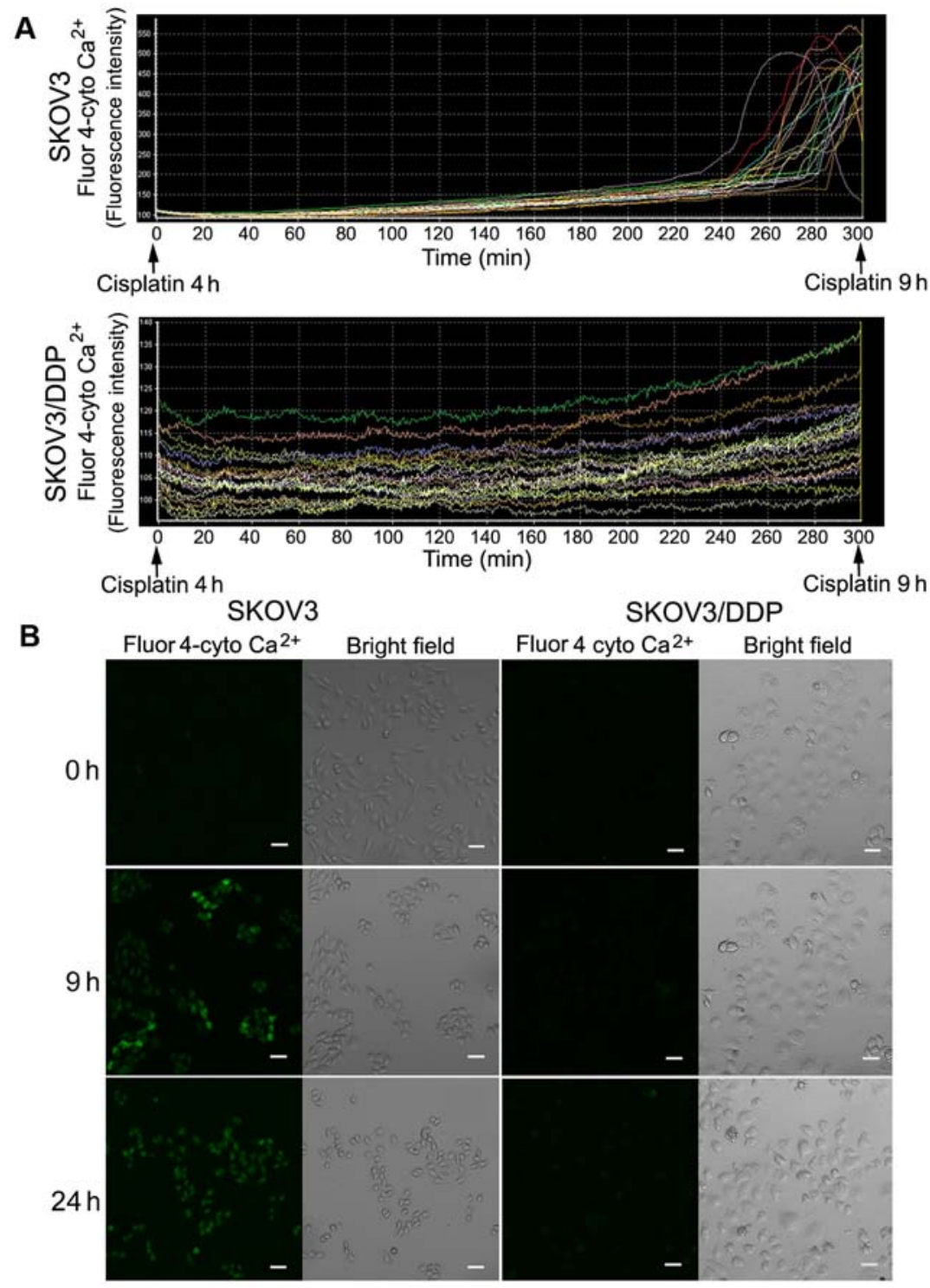

Figure 3. Cisplatin increases cytosolic $\mathrm{Ca}^{2+}$ levels in SKOV3 cells. (A) Both cell lines were treated with $6 \mu \mathrm{g} / \mathrm{ml}$ cisplatin for $9 \mathrm{~h}$ and time-lapse imaging was used to detect changes in cytosolic $\mathrm{Ca}^{2+}$ levels. Data were obtained by confocal laser microscopy. (B) Confocal microscopy was used to detect cytosolic $\mathrm{Ca}^{2+}$ levels in cells treated with $6 \mu \mathrm{g} / \mathrm{ml}$ cisplatin for 0,9 or $24 \mathrm{~h}$ (scale bar, $30 \mu \mathrm{m}$ ).

determined the apoptotic ratio bya quantitative analysis. Cisplatin increased the apoptotic ratio from $4.3 \%$ (at $0 \mathrm{~h}$ ) to $36.4 \%$ (at $24 \mathrm{~h}$ ) in the SKOV3 cells. In contrast, there were no obvious changes in the SKOV3/DDP cells over this period (Fig. 1C).

These results indicate that cisplatin can efficiently induce apoptosis in SKOV3 cells, but not in SKOV3/DDP cells.

Cisplatin induces ER stress in the SKOV3 cells but not in the SKOV3/DDP cells. To further evaluate the mechanism of cisplatin-induced apoptosis in ovarian cancer cells, we assessed ER stress protein expression in cells treated with cisplatin. Cisplatin treatment induced the expression of Grp78 and PDI, two ER stress marker proteins that accumulate after ER stress. Confocal microscopy showed that Grp78 and PDI accumulation occurred after $24 \mathrm{~h}$ in the SKOV3 cells treated with cisplatin (Fig. 2A and B). Western blotting showed that Grp78 and PDI were upregulated after $24 \mathrm{~h}$ in the
SKOV3 cells (Fig. 2C and D). We also detected upregulation of DDIT3/CHOP, which is involved in ER stress-induced cell death. These results showed that DDIT3/CHOP is induced in the cisplatin-treated SKOV3 cells (Fig. 2C and E). Caspase-4 is an ER-resident caspase that is processed in response to ER stress $(8,9,23)$. Caspase- 4 activation, reflected as caspase- 4 cleavage, was significantly increased in the SKOV3 cells after cisplatin treatment (Fig. 2C and E). Similarly, we determined that the expression of ATF4 and DDIT3/CHOP, two ER-stress mediators, was significantly upregulated in the SKOV3 cells treated with ER stress inducer, thapsigargin (TG) (Fig. 2F and G).

These results demonstrated that cisplatin can induce ER stress-mediated apoptosis in SKOV3 cells but not in SKOV3/DDP cells.

Cisplatin induces cytosolic $\mathrm{Ca}^{2+}$ influx in SKOV3 cells but not in SKOV3/DDP cells. The ER is the major intracellular calcium 

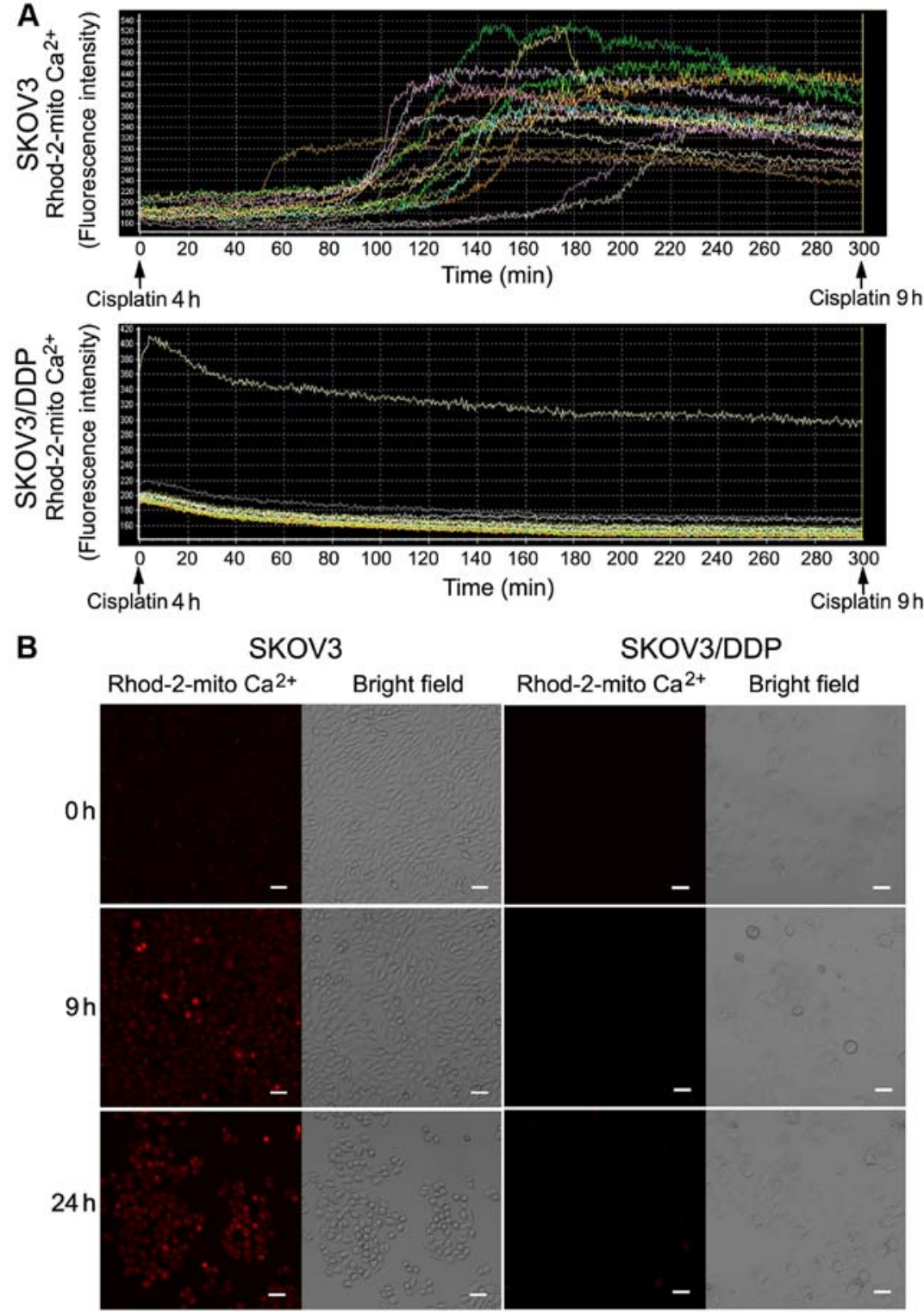

Figure 4. Cisplatin induces continuous $\mathrm{Ca}^{2+}$ influx into SKOV3 cell mitochondria. (A) Cisplatin elevates mitochondrial Ca ${ }^{2+}$ levels in the SKOV3 cells. Both cell lines were treated with $6 \mu \mathrm{g} / \mathrm{ml}$ cisplatin for $9 \mathrm{~h}$ and time-lapse scanning was used to detect the changes in mitochondrial $\mathrm{Ca}^{2+}$. Data were obtained by confocal laser microscopy. (B) Confocal microscopy was used to detect mitochondrial Ca ${ }^{2+}$ in cells treated with $6 \mu \mathrm{g} / \mathrm{ml}$ cisplatin for 0,9 or $24 \mathrm{~h}$ (scale bar, $30 \mu \mathrm{m}$ ).

$\left(\mathrm{Ca}^{2+}\right)$ storage organelle and is critically involved in $\mathrm{Ca}^{2+}$ homeostasis. Sustained ER stress causes $\mathrm{Ca}^{2+}$ release to the cytosol, leading to calcium overload. Thus, we investigated cytosolic $\mathrm{Ca}^{2+}$ changes using a calcium-sensitive fluorescent probe and confocal microscopy. We observed a sharp increase in cytosolic $\mathrm{Ca}^{2+}$ in the SKOV3 cells after $\sim 9 \mathrm{~h}$ of cisplatin treatment, but no obvious changes in the SKOV3/DDP cells (Fig. 3A).

Confocal microscopy images of both cell lines treated with cisplatin at 0,9 and $24 \mathrm{~h}$ showed a clear increase in green fluorescence after 9 and $24 \mathrm{~h}$ in the SKOV3 cells (Fig. 3B).

These results demonstrated that cisplatin induces calcium overload in SKOV3 cells, but not in SKOV3/DDP cells.

Cisplatin induces continuous $\mathrm{Ca}^{2+}$ flux into the mitochondria of SKOV3 cells. High cytoplasmic $\mathrm{Ca}^{2+}$ concentrations lead to increased mitochondrial $\mathrm{Ca}^{2+}$ uptake, which damage the mitochondria, leading to apoptosis. We measured mitochondrial $\mathrm{Ca}^{2+}$ changes using a calcium-sensitive fluorescent probe and confocal microscopy. There was a sharp increase in mitochondrial $\mathrm{Ca}^{2+}$ in the SKOV3 cells after cisplatin treatment for $\sim 6 \mathrm{~h}$, but a reduction in mitochondrial calcium in SKOV3/DDP cells (Fig. 4A).

Confocal microscopy images of both cell lines treated with cisplatin for 0,9 and $24 \mathrm{~h}$ showed a clear increase in red fluorescence after 9 and $24 \mathrm{~h}$ in the SKOV3 cells (Fig. 4B).

These results demonstrated that cisplatin can increase mitochondrial $\mathrm{Ca}^{2+}$ in SKOV3 cells, but not in SKOV3/DDP cells.

Mitochondrial $\mathrm{Ca}^{2+}$ overload leads to mitochondrial-mediated apoptosis in the SKOV3 cells. Mitochondrial calcium overload can damage the mitochondrial structure and induce apoptosis via the mitochondrial pathway. Therefore, our next goal was to determine the effect of mitochondrial $\mathrm{Ca}^{2+}$ overload on SKOV3 cells.

First, we used 5,5',6,6'-tetrachloro-1,1',3,3'-tetraethylbenzimidazolyL-carbocyanine chloride (JC-1) to measure 

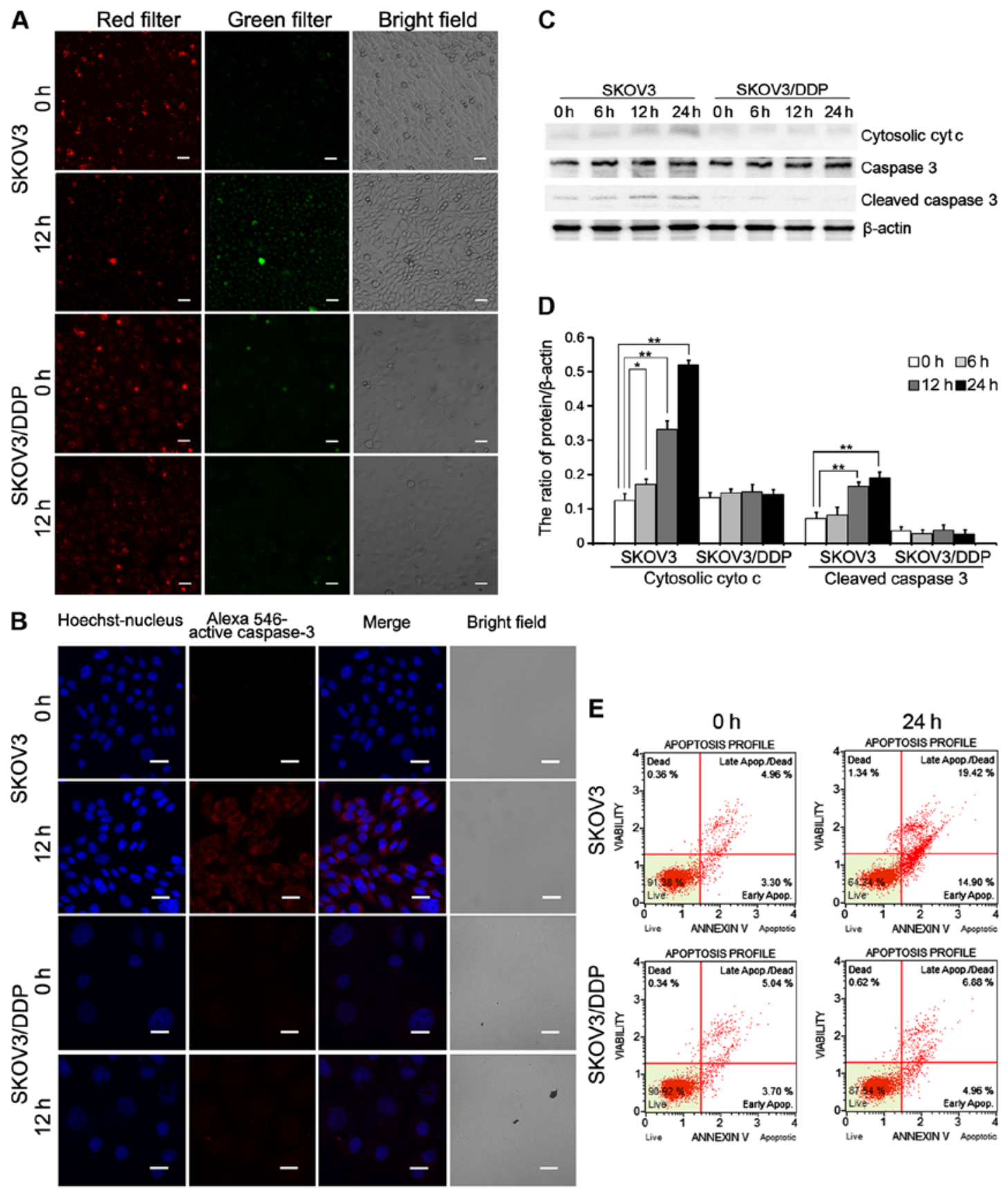

Figure 5. Mitochondrial $\mathrm{Ca}^{2+}$ overload leads to mitochondrial-mediated apoptosis in SKOV3 cells. (A) Both cell lines were treated with $6 \mu \mathrm{g} / \mathrm{ml}$ cisplatin for $12 \mathrm{~h}$, and the mitochondrial membrane potential was examined by JC-1 staining and confocal microscopy (scale bar, $30 \mu \mathrm{m}$ ). (B) Active caspase- 3 expression after cisplatin treatment for $12 \mathrm{~h}$ was detected by confocal microscopy (scale bar, $20 \mu \mathrm{m}$; Alexa Fluor 546-conjugated secondary antibody). (C) Western blot analysis of cytosolic cytochrome $c$, caspase-3 and cleaved caspase-3 expression in cells treated with cisplatin for $0,6,12$ or $24 \mathrm{~h}$. (D) Quantification of cytosolic cytochrome $c$ and cleaved caspase-3 protein. Data are presented as means $\pm \mathrm{SD}, \mathrm{n}=3$. ${ }^{*} \mathrm{P}<0.05$ vs. control, ${ }^{* *} \mathrm{P}<0.01$ vs. control. (E) Both cell lines were treated with $6 \mu \mathrm{g} / \mathrm{ml}$ cisplatin for $24 \mathrm{~h}$ and stained with Annexin V and Dead Cell reagent.

the mitochondrial membrane potential. The mitochondrial membrane potential started to decrease after cisplatin treatment for $12 \mathrm{~h}$ in the SKOV3 cells, but not in the SKOV3/ DDP cells (Fig. 5A).

Confocal microscopy showed caspase- 3 activation in both the SKOV3 and SKOV3/DDP cell lines treated with cisplatin. Cisplatin treatment increased caspase-3 activation in the SKOV3 cells relative to the SKOV3/DDP cells (Fig. 5B). As shown in Fig. 5C and D, cytosolic cytochrome $c$ and cleaved caspase-3 were upregulated in the SKOV3 cells compared with the SKOV3/DDP cells. Analysis of apoptosis by flow cytometry revealed a higher apoptosis rate in the SKOV3 cells treated with cisplatin $(34.32 \%)$ compared with the rate in the SKOV3/DDP cells exposed to cisplatin (11.84\%; Fig. 5E).

These results demonstrate that cisplatin-induced mitochondrial $\mathrm{Ca}^{2+}$ overload leads to mitochondrial-mediated apoptosis in SKOV3 cells.

Cisplatin-induced increase in mitochondrial-associated membrane structures leads to mitochondrial calcium overload in the SKOV3 cells. Mitochondrial-associated membranes (MAMs) linking ER to the mitochondria contain calcium 
A

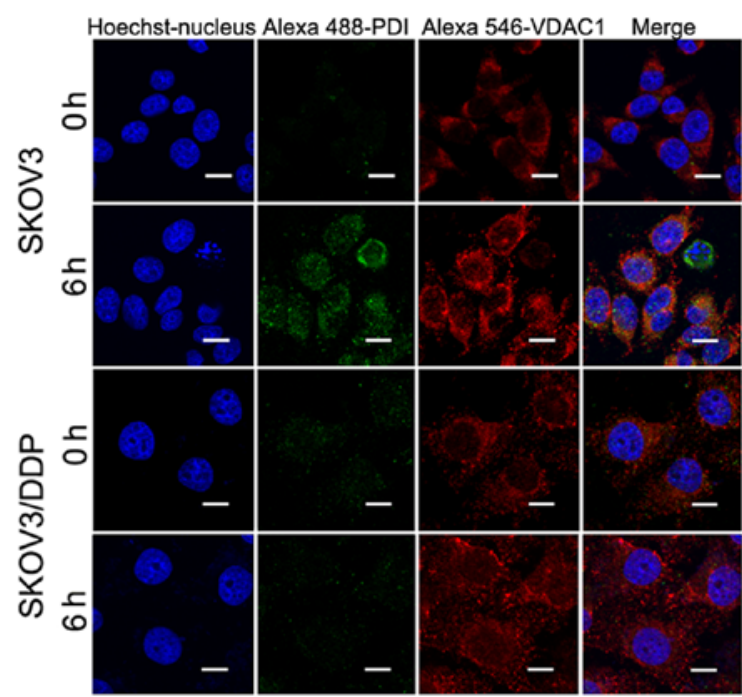

\section{C}
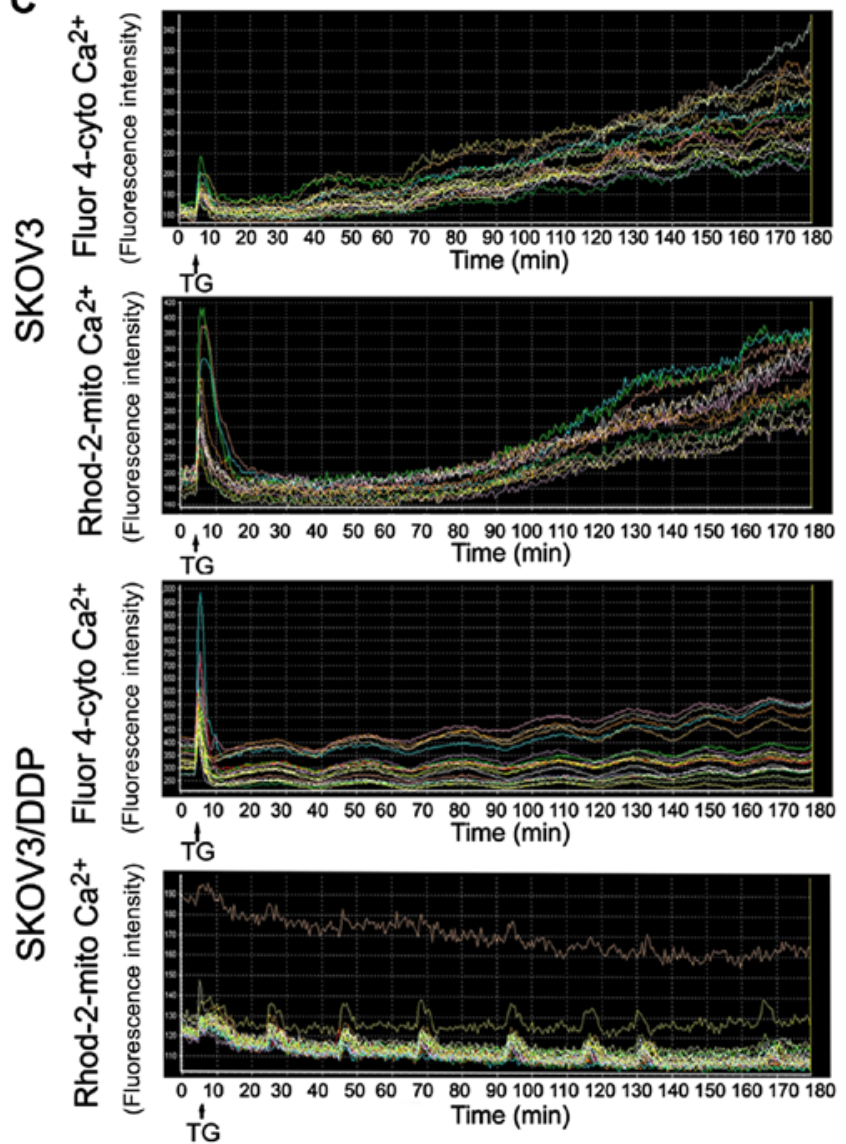

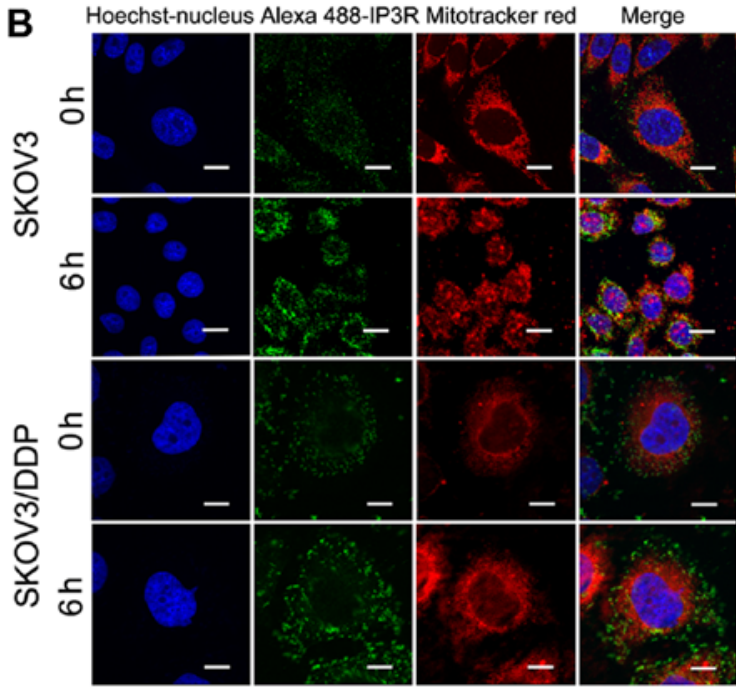

D

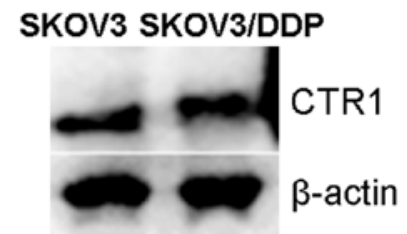

E

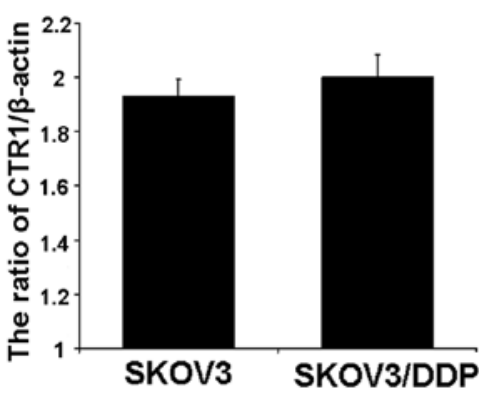

Figure 6. Cisplatin-induced changes in MAM structure lead to mitochondrial $\mathrm{Ca}^{2+}$ overload in SKOV3 cells. (A) Both cell lines were treated with $6 \mu \mathrm{g} / \mathrm{ml}$ cisplatin for $6 \mathrm{~h}$, and then the ER and mitochondria were labeled with anti-PDI and anti-VDAC1 antibodies, respectively. Changes in the number of ER-mitochondrial contacts were detected by confocal microscopy (scale bar, $10 \mu \mathrm{m}$; Alexa Fluor 488/546-conjugated secondary antibody). (B) Both cell lines were treated with $6 \mu \mathrm{g} / \mathrm{ml}$ cisplatin for $6 \mathrm{~h}$ and then IP3Rs and mitochondria were labeled with an anti-IP3R antibody and MitoTracker red, respectively. Changes in the number of ER-mitochondria contacts were detected by confocal microscopy (scale bar, $10 \mu \mathrm{m}$; Alexa Fluor 488-conjugated secondary antibody). (C) Both cell lines were treated with TG for $3 \mathrm{~h}$ and time-lapse scanning was used to detect changes in cytosolic and mitochondrial $\mathrm{Ca}^{2+}$. Data were obtained by confocal laser microscopy. (D) Western blot analysis of CTR1 expression in the SKOV3 and SKOV3/DDP cells. (E) Quantification of CTR1 protein. Data are presented as means $\pm \mathrm{SD}, \mathrm{n}=3$.

channels. Our results showed that mitochondrial calcium overload $(6 \mathrm{~h})$ occurred before cytosolic calcium overload $(9 \mathrm{~h})$. Therefore, we used ER and mitochondrial markers to observe structural changes in the MAMs after cisplatin treatment in both cell lines. In addition, confocal microscopy showed that
ER-mitochondria contact areas increased in the cisplatintreated SKOV3 cells (Fig. 6A and B).

We also test whether the ER stress inducer TG induced the same response in both cell lines. Using calcium-sensitive fluorescent probes, we found that the cytoplasmic $\mathrm{Ca}^{2+}$ 
concentration increased further after TG treatment; a parallel increase in mitochondrial $\mathrm{Ca}^{2+}$ concentration occurred in the SKOV3 cells, but not in the SKOV3/DDP cells (Fig. 6C). To investigate the role of CTR1 drug-importer on the acquisition of tolerance to cisplatin, we also detected CTR1 in the SKOV3 and SKOV3/DDP cells. According to Fig. 6D and E, expression of CTR1 in both cell lines exhibited no statistical differences.

These results demonstrated that SKOV3/DDP cells are more resistant to ER stress compared with SKOV3 cells.

\section{Discussion}

Chemotherapy resistance is a main cause of death in ovarian cancer patients $(3,24)$; identifying the resistance mechanism is therefore very important. Cisplatin is a classic chemotherapy reagent; drug resistance is mostly acquired and the mechanism is unclear. Cisplatin resistance may be caused by adaptive changes affecting multiple signaling molecules in tumor cells, for example, downregulation of apoptotic signaling and activation of pro-survival signaling. The ER is reported to be a cytoplasmic target of cisplatin $(8,9)$. Cisplatin can induce ER stress-associated apoptosis; therefore, ER stress tolerance may be involved in cisplatin resistance (6).

We used SKOV3/DDP cells as an in vitro model of cisplatin resistance. Morphometric analysis of cell apoptosis and analysis of cell viability after cisplatin treatment showed that the sensitivity of SKOV3/DDP cells to cisplatin was significantly lower than that of the parental SKOV3 cell line.

ER is the main storage organelle for intracellular $\mathrm{Ca}^{2+}$, and the site of protein synthesis, folding, modification and transport $(25,26)$. New proteins in the ER need to be modified in various ways, including glycosylation and disulfide bond formation, for correct folding, maturation and stabilization (26). These processes need the assistance of several resident molecular chaperones and $\mathrm{Ca}^{2+}$-binding proteins, including glucose-regulated proteins (such as Grp78 or $\mathrm{BiP}$ ), calreticulin and cadherin, and several protein-folding enzymes, such as protein disulfide isomerase (PDI) $(26,27)$. A variety of physiological and pathological conditions can interfere with the ER protein-folding process, leading to the deposition and aggregation of unfolded proteins in the ER, and resulting in ER stress that triggers the UPR (28). The primary function of the UPR is to reduce the burden of ER proteins by temporarily closing down protein synthesis and altering a complex gene transcriptional program to increase protein folding. If this transcriptional program cannot restore ER homeostasis, sustained ER stress induces cell death, known as ER-mediated apoptosis $(10,12,29)$. The main apoptotic effector molecule triggered by ER stress is DDIT3/CHOP $(12,29)$. DDIT3/CHOP switches on the expression of a series of genes, leading to apoptosis. Caspase-4 is an ER-resident caspase that is processed in response to ER stress; it is required for ER stress-induced apoptosis (similar to caspase-12 in murine cells) $(8,9,23,29,30)$. Active caspase- 4 enters the cytoplasm, where it activates other caspase family members to complete apoptosis $(30,31)$. In addition, ER stress-induced calcium signaling can also mediate cellular apoptosis $(12,29)$.

The present study showed that cisplatin treatment induced Grp78 and PDI expression in the SKOV3 cells, but not in the SKOV3/DDP cells. In addition, DDIT3/CHOP expression was increased and caspase-4 was activated in the SKOV3 cells. Moreover, when both SKOV3 and SKOV3/DDP cells were treated with TG, the expression levels of ATF4 and DDIT3/ $\mathrm{CHOP}$ were upregulated in the SKOV3 cells. These results indicated that cisplatin can trigger ER stress in the SKOV3 cells, leading to ER stress-mediated apoptosis. In contrast, SKOV3/ DDP cells were ER stress tolerant and did not undergo ER stress-mediated apoptosis.

Excessive ER stress synergizes with mitochondria and cytochrome $c$ to activate caspases and induce apoptosis $(16,32,33)$. The ER stress inducer TG induces ER stress, which triggers cytochrome $c$ release accompanied by elevated intracellular calcium (16). ER-mitochondria contacts represent many points of close contact between ER and mitochondria that can mediate the intermembrane exchange of lipids, calcium ions and glycosylated proteins $(19,20)$. ER-mitochondria contacts form the basis for two-way organellar communication that regulates mitochondrial energy and lipid metabolisms, $\mathrm{Ca}^{2+}$ signaling, and cell death during many physiological and pathological processes (18-20). ER-mitochondria contacts can mediate phospholipid and $\mathrm{Ca}^{2+}$ transport between the ER and mitochondria. This $\mathrm{Ca}^{2+}$ shuttling provides a convenient way to prevent pancytoplasmic non-specific upregulation of $\mathrm{Ca}^{2+}(17,21)$. The ER can release calcium ions, leading to calcium uptake by adjacent mitochondria to stimulate cell necrosis/apoptosis (18). Mitochondrial calcium overload can lead to reduced membrane potential, which causes cytochrome $c$ release and induces cell apoptosis $(17,34)$.

Our experiments showed that the cytoplasmic $\mathrm{Ca}^{2+}$ concentration in SKOV3 cells increased gradually with prolonged cisplatin treatment: a significant increase was observed at $\sim 9 \mathrm{~h}$, and it continued with longer exposure periods. In contrast, the mitochondrial $\mathrm{Ca}^{2+}$ concentration increased after $\sim 6 \mathrm{~h}$ and was then was maintained at the higher level. We further showed that in SKOV3 cells, cisplatin treatment for $6 \mathrm{~h}$ led to decreased mitochondrial membrane potential and cytochrome $c$ release, followed by caspase-3 activation. By labeling the ER and mitochondria, we found that cisplatin treatment clearly resulted in increased numbers of ER-mitochondria contact structures, which probably explains the rapid calcium influx from the ER into mitochondria after ER stress induction. These results suggest that when ER stress intensifies in SKOV3 cells, the number of connection structures between the ER and mitochondria increases, causing the ER to release large amounts of $\mathrm{Ca}^{2+}$ through the MAMs to the mitochondria; this happens before $\mathrm{Ca}^{2+}$ influx into the cytoplasm. In contrast, SKOV3/DDP cells are ER stress tolerant and do not exhibit this phenomenon; therefore, they survive.

We used the ER stress inducer TG to test this mechanism. In cisplatin-sensitive SKOV3 ovarian cancer cells, cytoplasmic $\mathrm{Ca}^{2+}$ levels rose rapidly to a peak, and then continued to rise, while the mitochondrial calcium concentration peaked sharply and then rose continuously. In contrast, in SKOV3/DDP cells, the cytoplasmic calcium level transiently increased and then fluctuated at a lower level; more importantly, the mitochondrial $\mathrm{Ca}^{2+}$ concentration did not increase significantly, although it showed cyclical fluctuations. These results indicated that cisplatin-resistant SKOV3/DDP cells have a strong tolerance to ER stress. The ER stress inducer TG did not induce cytosolic and mitochondrial calcium overload in this cell line. 
To the best of our knowledge, CTR1 has been found to regulate platinum drug uptake, such as cisplatin $(35,36)$. However, there was no significant difference in the expression of CTR1 between SKOV3 and SKOV3/DDP cells. This indicates that CTR1 plays no role in cisplatin-resistant SKOV3/DDP cells.

In conclusion, cisplatin-resistant SKOV3/DDP cells were used to study the role of ER stress in ovarian cancer cisplatin resistance. We found that cisplatin treatment did not induce ER stress in SKOV3/DDP cells, and that apoptosis signaling downstream of the UPR (related to ER stress) was not activated. Cytosolic or mitochondrial calcium overload did not occur in response to ER stress. The ER stress inducer TG also failed to induce calcium overload. This suggests that SKOV3/DDP cells are resistant to cisplatin-induced ER stress, and can thus avoid ER stress-mediated apoptosis to maintain cell survival, resulting in cisplatin resistance. These data provide new insights into the mechanism of cisplatin resistance in ovarian cancer.

\section{Acknowledgements}

This study was supported by the National Nature and Science Foundation of China (NSFC81372793, 81272876 and 81202552), and the Department of Education of Jilin Province Project (no. 2013361). We thank Liwen Bianji (Edanz Group China) for editing the English in this manuscript.

\section{References}

1. Mei L, Chen H, Wei DM, Fang F, Liu GJ, Xie HY, Wang X, Zou J, Han X and Feng D: Maintenance chemotherapy for ovarian cancer. Cochrane Database Syst Rev 6: CD007414, 2013.

2. Bookman MA: First-line chemotherapy in epithelial ovarian cancer. Clin Obstet Gynecol 55: 96-113, 2012.

3. Davis A, Tinker AV and Friedlander M: 'Platinum resistant' ovarian cancer: What is it, who to treat and how to measure benefit? Gynecol Oncol 133: 624-631, 2014.

4. Ali AY, Farrand L, Kim JY, Byun S, Suh JY, Lee HJ and Tsang BK: Molecular determinants of ovarian cancer chemoresistance: New insights into an old conundrum. Ann NY Acad Sci 1271: 58-67, 2012.

5. Galluzzi L, Senovilla L, Vitale I, Michels J, Martins I, Kepp O, Castedo M and Kroemer G: Molecular mechanisms of cisplatin resistance. Oncogene 31: 1869-1883, 2012.

6. Xu Y, Wang C and Li Z: A new strategy of promoting cisplatin chemotherapeutic efficiency by targeting endoplasmic reticulum stress. Mol Clin Oncol 2: 3-7, 2014.

7. Xu Y, Li D, Zeng L, Wang C, Zhang L, Wang Y, Yu Y, Liu S and Li Z: Proteasome inhibitor lactacystin enhances cisplatin cytotoxicity by increasing endoplasmic reticulum stress-associated apoptosis in HeLa cells. Mol Med Rep 11: 189-195, 2015.

8. Xu Y, Yu H, Qin H, Kang J, Yu C, Zhong J, Su J, Li H and Sun L: Inhibition of autophagy enhances cisplatin cytotoxicity through endoplasmic reticulum stress in human cervical cancer cells. Cancer Lett 314: 232-243, 2012.

9. Yu H, Su J, Xu Y, Kang J, Li H, Zhang L, Yi H, Xiang X, Liu F and Sun L: p62/SQSTM1 involved in cisplatin resistance in human ovarian cancer cells by clearing ubiquitinated proteins. Eur J Cancer 47: 1585-1594, 2011.

10. Groenendyk J and Michalak M: Endoplasmic reticulum quality control and apoptosis. Acta Biochim Pol 52: 381-395, 2005.

11. Yadav RK, Chae SW, Kim HR and Chae HJ: Endoplasmic reticulum stress and cancer. J Cancer Prev 19: 75-88, 2014.

12. Sano R and Reed JC: ER stress-induced cell death mechanisms. Biochim Biophys Acta 1833: 3460-3470, 2013.

13. Szegezdi E, Fitzgerald U and Samali A: Caspase-12 and ER-stress-mediated apoptosis: The story so far. Ann NY Acad Sci 1010: 186-194, 2003.

14. Hajnóczky G, Davies E and Madesh M: Calcium signaling and apoptosis. Biochem Biophys Res Commun 304: 445-454, 2003.
15. Santella L, Ercolano E and Nusco GA: The cell cycle: A new entry in the field of $\mathrm{Ca}^{2+}$ signaling. Cell Mol Life Sci 62: 2405-2413, 2005.

16. Deniaud A, Sharaf el dein O, Maillier E, Poncet D, Kroemer G, Lemaire $\mathrm{C}$ and Brenner $\mathrm{C}$ : Endoplasmic reticulum stress induces calcium-dependent permeability transition, mitochondrial outer membrane permeabilization and apoptosis. Oncogene 27: 285-299, 2008.

17. Pinton P, Giorgi C, Siviero R, Zecchini E and Rizzuto R: Calcium and apoptosis: ER-mitochondria $\mathrm{Ca}^{2+}$ transfer in the control of apoptosis. Oncogene 27: 6407-6418, 2008.

18. Grimm S: The ER-mitochondria interface: The social network of cell death. Biochim Biophys Acta 1823: 327-334, 2012.

19. Raturi A and Simmen T: Where the endoplasmic reticulum and the mitochondrion tie the knot: The mitochondria-associated membrane (MAM). Biochim Biophys Acta 1833: 213-224, 2013.

20. Rowland AA and Voeltz GK: Endoplasmic reticulum-mitochondria contacts: Function of the junction. Nat Rev Mol Cell Biol 13: 607-625, 2012.

21. Rizzuto R, Marchi S, Bonora M, Aguiari P, Bononi A, De Stefani D, Giorgi C, Leo S, Rimessi A, Siviero R, et al: $\mathrm{Ca}^{2+}$ transfer from the ER to mitochondria: When, how and why. Biochim Biophys Acta 1787: 1342-1351, 2009.

22. Luciani DS, Gwiazda KS, Yang TL, Kalynyak TB, Bychkivska Y, Frey MH, Jeffrey KD, Sampaio AV, Underhill TM and Johnson JD: Roles of IP3R and RyR Ca ${ }^{2+}$ channels in endoplasmic reticulum stress and beta-cell death. Diabetes 58: 422-432, 2009.

23. Liu N, Xu Y, Sun JT, Su J, Xiang XY, Yi HW, Zhang ZC and Sun LK: The BH3 mimetic S1 induces endoplasmic reticulum stress-associated apoptosis in cisplatin-resistant human ovarian cancer cells although it activates autophagy. Oncol Rep 30: 2677-2684, 2013

24. Galluzzi L, Vitale I, Michels J, Brenner C, Szabadkai G, HarelBellan A, Castedo M and Kroemer G: Systems biology of cisplatin resistance: Past, present and future. Cell Death Dis 5: e1257, 2014.

25. Ali Khan H and Mutus B: Protein disulfide isomerase a multifunctional protein with multiple physiological roles. Front Chem 2: 70, 2014.

26. Halperin L, Jung $\mathrm{J}$ and Michalak M: The many functions of the endoplasmic reticulum chaperones and folding enzymes. IUBMB Life 66: 318-326, 2014.

27. Koenig PA and Ploegh HL: Protein quality control in the endoplasmic reticulum. F1000Prime Rep 6: 49, 2014.

28. Chaudhari N, Talwar P, Parimisetty A, Lefebvre d'Hellencourt C and Ravanan P: A molecular web: Endoplasmic reticulum stress, inflammation, and oxidative stress. Front Cell Neurosci 8: 213, 2014.

29. Urra H, Dufey E, Lisbona F, Rojas-Rivera D and Hetz C: When ER stress reaches a dead end. Biochim Biophys Acta 1833: 3507-3517, 2013

30. Hitomi J, Katayama T, Eguchi Y, Kudo T, Taniguchi M, Koyama Y, Manabe T, Yamagishi S, Bando Y, Imaizumi K, et al: Involvement of caspase-4 in endoplasmic reticulum stressinduced apoptosis and Abeta-induced cell death. J Cell Biol 165: 347-356, 2004.

31. Oda T, Kosuge Y, Arakawa M, Ishige K and Ito Y: Distinct mechanism of cell death is responsible for tunicamycin-induced ER stress in SK-N-SH and SH-SY5Y cells. Neurosci Res 60: 29-39, 2008.

32. Dou G, Sreekumar PG, Spee C, He S, Ryan SJ, Kannan R and Hinton DR: Deficiency of $\alpha \mathrm{B}$ crystallin augments ER stressinduced apoptosis by enhancing mitochondrial dysfunction. Free Radic Biol Med 53: 1111-1122, 2012.

33. Rodriguez D, Rojas-Rivera D and Hetz C: Integrating stress signals at the endoplasmic reticulum: The BCL-2 protein family rheostat. Biochim Biophys Acta 1813: 564-574, 2011.

34. Chaudhuri D and Clapham DE: Outstanding questions regarding the permeation, selectivity, and regulation of the mitochondrial calcium uniporter. Biochem Biophys Res Commun 449: 367-369, 2014.

35. Fung KL, Tepede AK, Pluchino KM, Pouliot LM, Pixley JN, Hall MD and Gottesman MM: Uptake of compounds that selectively kill multidrug-resistant cells: The copper transporter SLC31A1 (CTR1) increases cellular accumulation of the thiosemicarbazone NSC73306. Mol Pharm 11: 2692-2702, 2014.

36. Matsumoto S, Tanaka T, Kurokawa H, Matsuno K, Hayashida $Y$ and Takahashi T: Effect of copper and role of the copper transporters ATP7A and CTR1 in intracellular accumulation of cisplatin. Anticancer Res 27: 2209-2216, 2007. 